\title{
Benutting van landbouneweprodukte en gesuiwerde rioolwater in akwakultuur in ontwikkelende gebiede van Suid-Afrika
}

\author{
J.F. Prinsloo* \\ Akwakultuurnavorsingseenheid, Universiteit van die Noorde, Sovenga 0727 \\ H.J. Schoonbee \\ Departement Dierkunde, Randse Afrikaanse Universiteit, Johannesburg 2000 \\ Ontvang 28 April 1993; aanvalar 2 Augustus 1993
}

\section{UITTREKSEL}

Die ernstige tekort aan water vir huishoudelike, landbou- en nywerheidsgebruik noodsaak die optimale benutting van hierdie skaars hulpbron in Suid-Afika. Die gelyktydige aanwending van water in geintegreerde voedselproduksiesisteme, waar dieselfde volume water benut word vir vis-, eend-en groenteproduksie, is een wyse waarop water veeldoelig benut kan word. Landbouafvalstowwe soos o.a. hoender-, bees- en eendemis is aangewend as organiese bemestingstowwe om die visproduksiepotensiaal daarvan, met en sonder bykomende voeding, in visdamme te evalueer. Die invloed van watertemperatuur op die visproduksiepotensiaal is ook ondersoek. Gebruik is gemaak van 'n kombinasie van visspesies bestaande uit Europese en Sjinese karpspesies asook die skerptandhaber, om die verskillende trofiese vlakke in 'n visdam-ekostelsel optimaal te benut. Byvoeding het uit 1845\% proteien-vispille bestaan. As alternatief tot organiese bemesting is die produksiepotensiaal van behandelde rioolwater met die byvoeging van vispille in vismono- en -polikultuursisteem ook ondersoek. Die Europese karp en die skerptandbaber is vir die doel gebruik. Die moontlike waarde van sodanige geïntegreerde landbou-akwakultuursisteme vir landelike swart gemeenskapsontwikkelingprogramme word bespreek.

\section{ABSTRACT}

\section{The utilization of agricultural by-products and treated effluent water for aquaculture in developing areas of South Africa}

The serious shortage of potable water supplies for domestic, agricultural and industrial requirements necessitates an investigation into the optimal utilization of this scarce commodity in South Africa. The multipurpose use of water in agriculture through its effective utilization in integrated aquaculture-agriculture food production systems is one way of optimising the application of such water. In the present series of investigations, agricultural wastes such as chicken, cattle and duck manure were applied as organic nutrient in freshwater fish ponds with and without supplementary feeds. Fish used in polyculture production for the optimal utilization of the various trophic levels in manured fish pond ecosystems included the European and Chinese carp species and the sharptooth catfish. Supplementary food consisted of 18-45\% protein fish pellets. As an alternative to organic manures, treated sewage effluent with fish pellets was used to evaluate its fish-production potential. Fish species used in monoculture and polyculture production included the European common carp and the sharptooth catfish. The role of water temperature on the fish-production potential of these systems was also investigated. The possible value of integrated aquaculture-agriculture systems in protein production in rural community development in South Africa is discussed.

Volgens bevolkingskattingstatistieke is daar tans 32 miljoen mense in Suid-Afrika, wat teen die einde van hierdie eeu tot 47 miljoen sal toeneem.

Suid-Afrika se potensiële oppervlak- en ondergrondse watervoorrade kan onder normale reëntoestande slegs 'n bevolking van 80 miljoen mense onderhou, ${ }^{2}$ wat volgens pojeksies reeds teen die jaar 2020 bereik sal word, waarna 'n ernstige tekort aan voedsel gekoppel aan wanvoeding, veral in plattelandse ontwikkelende gebiede, mag voorkom. ${ }^{3}$ In die lig hiervan moet daar dus ernstig gekyk word na die werklike en optimale voedselproduksiepotensiaal van alle beskikbare watervoorrade in veral die ontwikke- lende gebiede van Suid-Afrika. Die optimale benutting van ons beskikbare besproeiings- en ander water is dus van groot belang. Die integrering van akwakultuur by landbouproduksie bied dan ook 'n gulde geleentheid hiervoor.

As gevolg van intensiewe boerderypraktyke met vee, insluitende pluimvee, word daar tans ernstige potensiële gesondheids- en besoedelingsprobleme geskep deur die opeenhoping van dierlike misstowwe. ${ }^{4}$ Deur hierdie misstowwe in visdamme aan te wend, 5,6,7,8,9,10 kan 'n netelige probleem op 'n higiëniese wyse opgelos word, terwyl die nutriënte wat daarin voorkom, aangewend kan 
word om die verskillende trofiese vlakke van visdamekosisteme optimaal te stimuleer. Deur die regte keuse van visspesies te maak wat elk op 'n bepaalde komponent van 'n visdam-ekosisteem voed, word die potensiële produktiwiteit van die afvalstof omskep in diereproteien, nl. vis.

Die kwaliteit van die uitvloeiwater by rioolsuiweringswerke is gewoonlik van hoogstaande gehalte met heelwat nutriënte daarin en is ook geskik om sonder byvoeging van addisionele viskos, 'n redelike konstante visproduksie te handhaaf. $11,12,13,14$

In hierdie artikel word aandag gegee aan die benutting van landbou-afvalstowwe in visproduksie en die optimale benutting van visdam-ekosisteme deur gebruik te maak van vispolikultuurtoestande. Vervolgens word die aandag gevestig op die integrering van akwakultuur by die landbou deur bv. vis, eende en groente met dieselfde watervolume te produseer. Die visproduksiepotensiaal van rioolwateruitvloeisels in die produksie van die skerptandbaber en die Europese karp, word ook bespreek.

Met die oog op die visproduksie-ondersoeke, is tegnieke ontwikkel en aangepas by plaaslike omstandighede om al die vermelde vissoorte, met die uitsondering van Micropterus salmoides, op 'n groot skaal met behulp van hormone te produseer. ${ }^{41,42,43,44,45,46,47,48,49}$ Ondersoeke is ook gedoen na die gebruik van lewende voedsel, soos soöplankton, in die vroeë larwale ontwikkeling van die genoemde spesies. ${ }^{48,50}$

\section{MATERIAAL EN METODES}

Die vrystelling van landbou-afvalstowwe soos bees-, skaap-, vark- en hoendermis in visdamme is verantwoordelik vir die ontwikkeling van komponente soos fitoplankton, soöplankton, soöbentos en makrofiete. Visse wat hierdie onderskeie komponente kan benut, sluit die volgende spesies in:

1. Die bloukurper Oreochromis mossambicus (Peters) wat 'n detritus- en fitoplanktonvoeder is. ${ }^{15,16,17,18}$ Hierdie vis benut selfs draadalge wat in organies verrykte visdamme mag ontwikkel. ${ }^{19}$ Die visspesie kan egter net in die warmer streke van ons land doeltreffend gebruik word waar winterwatertemperature nie benede $12^{\circ} \mathrm{C}$ daal nie.

2. Die Sjinese silwerkarp Hypophthalmicthys molitrix (Val.) wat spesifiek 'n detritus- en fitoplanktonvoeder is. $20,21,22,23,24,25,26$

3. Die Sjinese dikkopkarp Aristichthys nobilis (Richardson) wat hoofsaaklik op soöplankton voed maar ook fitoplankton en detritus kan benut. ${ }^{20,22,25,26,27}$

4. Die Sjinese graskarp Ctenopharyngodon idella (Val.) is 'n makrofietvoeder $20,24,25,28,29,30,31,32$ en word vandag algemeen in Suid-Afrika gebruik om onderwatermakrofiete, wat in organies besoedelde water voorkom, te benut. ${ }^{33,34}$

5. Die Sjinese swartkarp Mylopharyngodon piceus (Richardson) wat 'n uitstekende slakvoerder is en aktief op Lymnaea-, Bulinus- en selfs Melanoidesspesies voed. ${ }^{20,25,35,36}$
6. Die gewone Europese karp Cyprinus carpio is 'n soöbentosvoeder wat aktief voed op die bentiese fauna wat in visdamme ontwikkel. ${ }^{20,25.26,37}$

7. Predatore en omnivore sluit visspesies in soos o.a. die grootbek-swartbaars Micropterus salmoides ${ }^{38}$ en die skerptandbaber Clarias gariepinus. ${ }^{39}$ Hierdie twee visspesies word ondermeer aangewend in die beheer van kleinvis en die platanna Xenopus laevis wat in die visdamme mag uitbroei. ${ }^{40}$

\section{EKSPERIMENTE}

\section{Hoendermis sonder byvoeding}

Die totale getal vis wat in polikultuur aangehou is, was 7700 per hektaar. Die visspesiekombinasie en die persentasie individuele bydraes het bestaan uit $C$. carpio $(62,3 \%), M$. piceus $(7,8 \%)$ en $H$. molitrix $(22,0 \%) .^{51}$

Vars hoendermis is direk in die water van die visdamme toegedien. Hoendermis by bepaalde konsentrasies, wat neergekom het op 'n aanvanklike droëmassaekwivalent van $7 \%$ van die totale geskatte vismassa in die damme, is vyfdaagliks toegedien. Na 'n tydperk van 4 weke is die persentasie toediening van hoendermis verminder tot $3-5 \%$. Hierdie stap was veral nodig as gevolg van die afname in watertemperature benede $20^{\circ} \mathrm{C}$ gedurende die laat somer en die verwagte afname in visvoedingsaktiwiteite. Die visproduksieperiode het 160 dae geduur.

\section{Hoendermis met byvoeding}

'n Totaal van 9400 vis is per hektaar aangehou. Visspesiesamestelling en die persentasieverteenwoordiging vir die onderskeie vis was: $C$. carpio $51,0 \%, M$. piceus $6,4 \%, C$. idella $6,4 \%, H$. molitrix $18,1 \%$ en $O$. mossambicus $18,1 \% .^{51}$ Hoeveelhede hoendermis in visdamme met byvoeding was basies dieselfde as dié vir damme waar slegs hoendermis vir die duur van die eksperiment toegedien is. Met 'n afname in visproduksie is 'n 45\%-proteïenviskos, naas die mistoediening, daagliks toegedien teen 'n berekende aangepaste verhouding van $4 \%$ van die geskatte totale vismassa in die visdamme. Die toediening van hoendermis is terselfdertyd verminder na $3 \%$ (bereken op droëmassabasis) van die totale vismassa gedurende die somermaande. Daaglikse toediening van hoendermis is verder verminder na $2 \%$ met 'n afname in watertemperatuur onder $20^{\circ} \mathrm{C}$. Die visproduksieperiode het 160 dae geduur.

Die resultate van hoendermis, met en sonder byvoeding, word in figuur I saamgevat.

\section{Beesmis sonder byvoeding}

'n Totaal van 7700 vis per hektaar is in polikultuur aangehou. Visspesiesamestelling en persentasieverteenwoordiging was soos volg: $C$. carpio $62,3 \%, M$. piceus $7,8 \%, C$. idella $7,8 \%$ en $H$. molitrix $22,0 \%{ }^{52}$ Vars beesmis is vir 5 dae per week toegedien teen 'n berekende aangepaste hoeveelheid van $4 \%$ (droë massa) van die totale geskatte vismassa in elke dam. Om optimale groei te stimuleer, is mistoediening verhoog na 6-7\% vanaf weke 10-14. Namate die watertemperatuur in die visdamme 
onder $20^{\circ} \mathrm{C}$ gedaal het, is die hoeveelheid mis toegedien verminder tot $3 \%$. Die stap was veral nodig om lae suurstofvlakke van die water in die visdamme te vermy. Die visproduksieperiode is vir 160 dae volgehou.

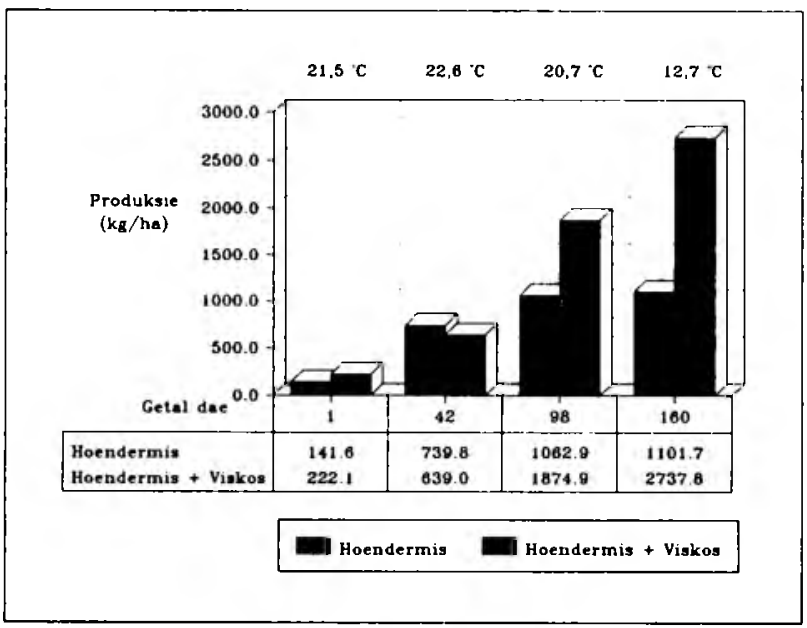

FIGUUR 1: Vispolikultuurproduksiedata ( $\mathrm{kg} / \mathrm{ha}$ ) oor 'n periode van 160 dae met hoendermis as organiese bemesting en 'n 45\%-proteienviskos as byvoeding. Gemiddelde watertemperature vir elke tydperk in ${ }^{\circ} \mathrm{C}$.

\section{Beesmis met byvoeding}

'n Totaal van 9400 vis per hektaar is in polikultuur aangehou. Die visspesiesamestelling en persentasieverteenwoordiging was soos volg: $C$. carpio $51,0 \%, M$. piceus $6,4 \%, C$. idella $6,4 \%, H$. molitrix $18,1 \%$ en $O$. mossambicus $18,1 \% .{ }^{52}$ Die aanvanklike dosistoediening van beesmis is konstant gehou op $4 \%$ (droë massa) van die geskatte totale vismassa vir die eerste 50 dae van die produksieperiode. Hierna is dit verminder tot $3 \%$ en met die afname in watertemperatuur onder $20{ }^{\circ} \mathrm{C}$ is mistoediening verder verminder tot $2 \%$ van die totale geskatte vismassa om suurstofprobleme te voorkom. 'n $45 \%$-proteienviskos is vanaf dag 51 , naas die mistoediening teen 'n berekende verhouding van $4 \%$ van die totale geskatte vismassa toegedien. $\mathrm{Na} 72$ dae is die daaglikse viskostoediening tot 3\% verminder. Die visproduksieperiode het 160 dae geduur.

Die resultate van beesmis, met en sonder byvoeding, word in figuur 2 weergegee.

Visproduksie met behulp van geïntegreerde vis-, eend- en groenteproduksiesisteme

Die totale getal vis wat in polikultuur aangehou is, was 12500 per hektaar. Die persentasie individuele bydrae was soos volg: $C$. carpio $56,0 \%, A$. nobilis $8,0 \%, C$. idella $6,2 \%$ en $H$. molitrix $30,0 \%{ }^{53}$

Jong eende van 27 dae oud is aangehou en op visdamme gevoed. Die damme is so ingerig dat feitlik alle vars eendemis direk in die visdamme vrygestel is. Die digtheid van die eende was 2500 per hektaar. Binne 27 dae na uitplasing op die visdamme het die eende bemarkbare massas bereik. Vyf opeenvolgende groepe eende kon dus binne 'n groeiseisoen van 149 dae markklaar gemaak word.

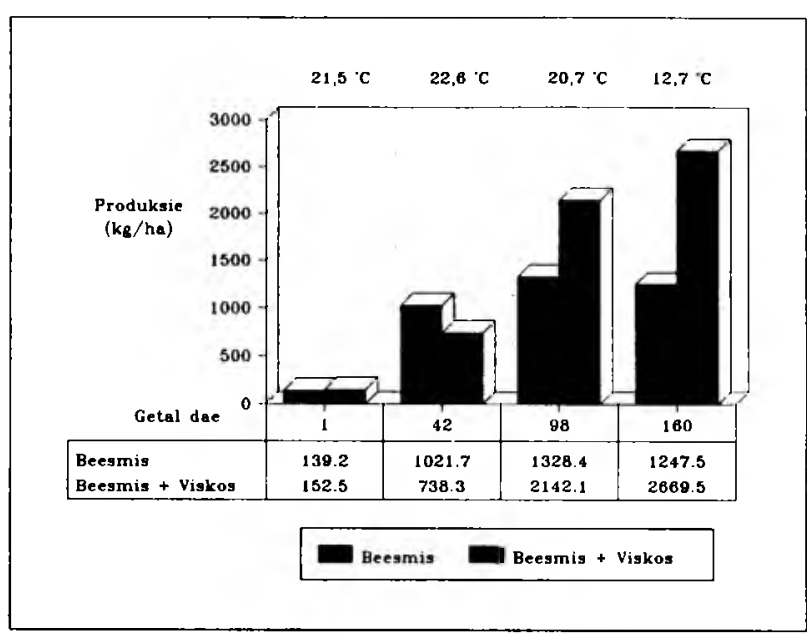

FIGUUR 2: Vispolikultuurproduksiedata ( $\mathrm{kg} / \mathrm{ha}$ ) oor 'n periode van 160 dae met beesmis as organiese bemesting en in 45\%-proteienviskos as byvoeding. Gemiddelde watertemperature vir elke tydperk in ${ }^{\circ} \mathrm{C}$.

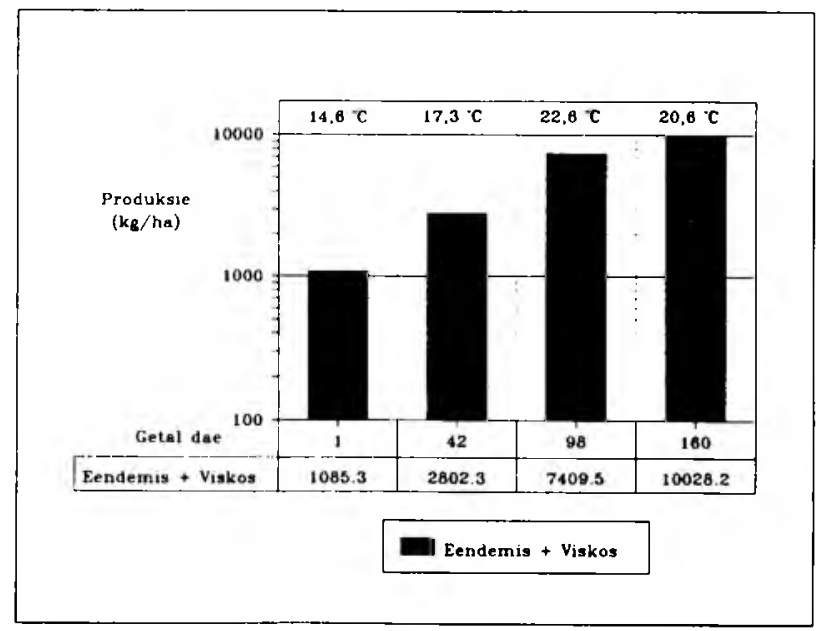

FIGUUR 3: Vispolikultuurproduksiedata ( $\mathrm{kg} / \mathrm{ha}$ ) oor 'n periode van 149 dae met vars eendemis as nutriënt en 'n 18\%-proteienviskos as byvoeding. Gemiddelde watertemperature vir elke tydperk in ${ }^{\circ} \mathrm{C}$.

Visvoedsel is toegedien teen $4 \%$ van die berekende massa van die gewone karp, C. carpio, in die visbevolking van elke dam. Die nutriëntryke water van die visdamme is aangewend vir die besproeiing van verskeie groentesoorte. Groentesoorte wat verbou is, het beet, slaai, aartappels, spinasie en tamaties ingesluit. Groente is versigtig ge-oes en noukeurig geweeg voordat dit aan die plaaslike bevolking verkoop is teen ' $n$ winsgewende marge, maar steeds teen 'n relatief lae prys. As kontrole is water gebruik wat vry was van nutriënte om dieselfde groetegewasse onder identiese digthede per hektaar oor dieselfde periode, te besproei.

In figuur 3 word die produksie van $\mathrm{kg} / \mathrm{ha}$ vis, wanneer vars eendemis as nutriënt gebruik word, aangetoon. 


\section{Benutting van rioolafloopwater in visproduksie}

In die huidige reeks ondersoeke na die potensiaal van rioolwater vir visproduksie ${ }^{54.55}$ is twee vissoorte, nl. die Europese karp $C$. carpio en die skerptandbaber C. gariepinus gebruik. Sowel mono- as polikultuurproduksieproewe is uitgevoer. Visdigthede het tussen 10000 en 11045 vis per hektaar gewissel. In die polikultuurproduksieproef is 5575 karp en 5470 baber per hektaar gebruik. Gelyke getalle karp en baber, t.w. 10000 is in die monokultuurproewe gebruik. 'n Laeproteienviskos (18\%) is as aanvullende rantsoen toegedien. Voedseltoediening het aanvanklik geskied teen $2 \%$ van die berekende totale vismassa in die damme. Na 28 dae is die hoeveelheid viskos toegedien tot $4 \%$ verhoog. Die totale duur van die produksieproewe was 100 dae vir die polikultuur- en 126 dae vir die monokultuurproduksieproewe. In 'n poging om suurstofprobleme te voorkom, is die totale hoeveelheid voedsel per dag oor vier voedingsperiodes versprei. In die polikultuurproduksieproewe is bemarkbare vis reeds vanaf dag 70 genet en verkoop. Alle oorblywende vis in beide produksieproewe het voor of op 126 visproduksiedae bemarkbare groottes bereik.

In figuur 4 word die produksie van karp en baber in 'n behandelde rioolwatermedium waar proteïenviskos as byvoeding gebruik is, saamgevat.

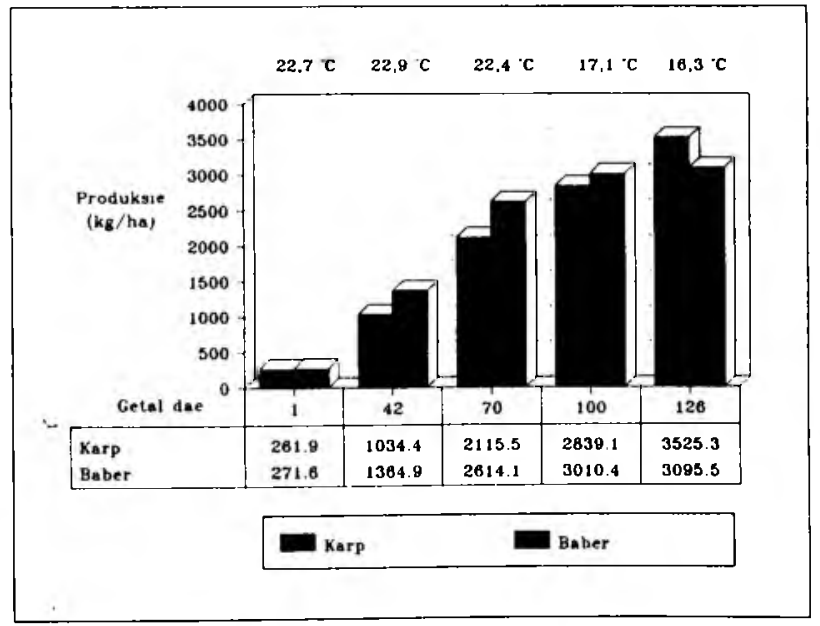

FIGUUR 4: Aanwending van behandelde rioolwater in die monokultuurproduksie van die karp $\mathrm{C}$. carpio en die baber C. gariepinus oor 'n tydperk van 126 dae. 'n 18\%proteienviskos is as byvoeding gebruik. Gemiddelde watertemperature vir elke tydperk in ${ }^{\circ} \mathrm{C}$.

\section{RESULTATE}

Die hoeveelheid mis aangewend in visdamme in die visproduksie-ondersoeke oor 'n periode van 150-160 dae, word in tabel 1 aangegee.

Die resultate wat gelewer is met die aanwending van gemelde organiese misstowwe, sonder dat oor 'n periode van 5-6 maande suurstofprobleme in visdamme ondervind is, het bewys gelewer dat dit wel moontlik is om vis op hierdie wyse te produseer sonder die gevaar van vismortaliteite. Gedurende hierdie tydperk was die minimumkonsentrasie vir suurstof in die dag selde laer as $15 \%$ van die versadigingspunt vir enige van die misstowwe wat toegedien is. Belugting was slegs gedurende die tweede helfte van die visproduksieperiode nodig. Indien die hoeveelhede vars mis wat toegedien is in ag geneem word, was die konsentrasiewaardes vir ammoniak in die visdamwaters tydens al die ondersoeke nooit buitengewoon hoog nie. Dit geld ook vir die $\mathrm{pH}$ en die fosfaatkonsentrasies in die water. Besproeiing van nutriëntryke water op groentetuine het die verdere voordeel ingehou dat die ladings opgeloste en gesuspendeerde organiese materiaal in die visdamme betreklik laag gebly het.

TABEL 1

Hoeveelheid mis, gebaseer op nat en droë massa, in visdamme toegedien oor 'n periode can 150-160 dae. Waardes uitgedruk in $\mathrm{kg} / \mathrm{ha}$

\begin{tabular}{|l|l|r|r|}
\hline Tipe mistoediening & \multicolumn{3}{|c|}{ Massa van mis toegedien in $\mathrm{kg} / \mathrm{ha}$} \\
\hline & & Nat massa & Droë massa \\
\hline Beesmis & Sonder viskos & 51132 & 9023 \\
& Met viskos & 38522 & 6796 \\
\hline Hoendermis & Sonder viskos & 10664 & 9273 \\
& Met viskos & 8096 & 7040 \\
\hline Eendemis & Met viskos & $46766^{*}$ & $32269^{*}$ \\
\hline
\end{tabular}

* Berekende waardes gebaseer op hoeveelhede voedsel gebruik.

Visproduksieresultate wat in verband gebring word met die aanwending van hoendermis as nutriënt sonder en met byvoeding

Soos afgelei kan word uit figuur I was die visopbrengs reeds I ton na 160 dae. Hiervan was alreeds meer as $62 \%$ van die totale vismassa binne die eerste 42 dae geproduseer. Die data toon verder dat watertemperature 'n uiters belangrike en kritiese rol speel in die omsetting van voer en mis na visproteïen. Sodra die gemiddelde watertemperature in die visdamme byvoorbeeld onder 20 ${ }^{\circ} \mathrm{C}$ daal, tree 'n dramatiese verlaging in visproduksie in.

In die geval waar byvoeding toegedien is (fig. 1), was die visproduksie aan die einde van die produksieperiode bykans drie keer so hoog as dié sonder byvoeding, t.w. 2 $738 \mathrm{~kg}$ per hektaar. Wat baie belangrik is, is dat die gemiddelde voeromset gedurende die eerste 70 dae slegs $1,4: 1$ was. Met 'n verlaging in watertemperature onder $20{ }^{\circ} \mathrm{C}$, tree daar egter 'n dramatiese verswakking in voeromsette in en was dit 3,1:1 teen dag 128. Met 'n verdere daling in watertemperatuur tot gemiddeld $12,7^{\circ} \mathrm{C}$, het die voeromset verder verswak tot 5,9:1. Waar die gemiddelde visproduksie vir hoendermis alleen $7,0 \mathrm{~kg} /$ hektaar/dag was, het byvoeding die gemiddelde produksie tot $15,0 \mathrm{~kg} /$ hektaar $/$ dag verhoog. 
Visproduksieresultate wat in verband gebring word met die gebruik van beesmis as nutriënt sonder en met byvoeding

In die geval van die aanwending van beesmis as nutriënt in visdamme (fig. 2), is daar bevind dat $73 \%$ van die totale visproduksie reeds binne die eerste 42 dae bereik is. In daardie stadium was daar reeds $1021 \mathrm{~kg}$ vis/hektaar geproduseer. ' $\mathrm{n}$ Daling in watertemperatuur benede $20^{\circ} \mathrm{C}$ toon, netsoos vir die hoendermisproduksieproewe, ' $n$ drastiese verlaging in visproduksietempo en kon slegs 'n verdere $332 \mathrm{~kg}$ /hektaar toegevoeg word tot die totale visopbrengs oor 160 dae. 'n Verlaging in watertemperature tot minder as $20{ }^{\circ} \mathrm{C}$ het $n$ heelwat swakker omskakeling van organiese misstowwe deur die verskillende trofiese vlakke van die visdam-ekosisteem na visproteien tot gevolg gehad. So byvoorbeeld verswak die beesinisomsette na vismassa vanaf 10,2:1 gedurende die eerste 70 dae van die produksieproewe tot $26,3: 1$ tussen dae 70 en 98 en tot $44,6: 1$ na 128 dae. Die gemiddelde visproduksie deur gebruik te maak van beesmis alleen, was $9,2 \mathrm{~kg} /$ hektaar $/ \mathrm{dag}$.

Waar byvoeding saam met beesmis toegedien is (fig. 2), het visproduksie toegeneem tot $2669 \mathrm{~kg} /$ hektalar na 160 dae. Byvoeding het die visproduksie vanaf 9,2 tot 16,4 $\mathrm{kg} /$ hektaar/dag verhoog. Die hoogste produksiesyfer wat $30 \mathrm{~kg}$ /hektaar/dag oorskry het, het voorgekom tydens die periode toe die gemiddelde watertemperatuur in die visdamme nog sowat $20^{\circ} \mathrm{C}$ was.

Visproduksieresultate wat in verband gebring word met die gebruik van eendemis met byvoeding as nutriënt

Soos afgelei kan word uit figuur 3 was die heel beste van alle resultate verkry in die visproduksieproewe waar eende op die visdamme gehou is en waar vars eendemis direk in die visdamwater vrygestel is. Met hierdie benadering was dit moontlik om 8,94 ton vis/hektaar na slegs 149 dae te produseer met 'n totale gemiddelde voeromset van 1,9:1. 'n Belangrike faktor wat onder meer hier 'n rol gespeel het, was dat daar gebruik gemaak is van oorwinterde jong vis en dat die produksieproef reeds beëindig kon word terwyl die gemiddelde visdamwatertemperatuur nog hoër as $20^{\circ} \mathrm{C}$ was. Vergeleke met die ander vorme van mis- en byvoedingtoediening, was die gemiddelde visproduksie aansienlik hoër, t.w. $61,7 \mathrm{~kg} /$ hektaar/dag.

\section{Produksie van eende op visdamwater}

Behalwe vir die feit dat die eende besonder skoon gebly het op die visdamme en die bruikbaarheid van die vere as gevolg daarvan aansienlik verbeter het, was dit moontlik om meer as 6,6 ton eende per hektaar op die visdamme binne 'n periode van 28 dae te produseer. Die gemiddelde eendproduksie het neergekom op $161 \mathrm{~kg} /$ hektaar/dag. Die empiriese gegewens toon duidelik dat dit moontlik is om 32 ton eende per hektaar op visdamme te produseer gedurende 'n ses maande somergroeiseisoen.

\section{Groenteproduksie met behulp van nutriëntryke water vanaf visdamme}

Die verskillende gewasse wat met nutriëntryke water vanaf die eend-visdamme besproei is, asook varswater en die produksieresultate vir elke gewas, word in tabel 2 aangegee. Die resultate word uitgedruk in $\mathrm{kg} /$ hektaar groente geproduseer. Volgens die resultate het tamaties die hoogste produksie per hektaar vir beide watertipes wat gebruik is, opgelewer. In die geval waar besproeiingswater vanaf die eend-visdamme gebruik is, is byna 96 ton tamaties/hektaar geproduseer, teenoor 'n produksie van 64,5 ton/hektaar waar slegs varswater gebruik is. Spinasie en slaai het eweneens merkbaar beter resultate opgelewer waar daar van die organies verrykte besproeiingswater gebruik gemaak is. In die geval van aartappels was die produksie egter byna vier ton per hektaar hoër waar onbemeste water gebruik is. Die laagste produksie vir al die gewasse is vir beet waargeneem. Hier het bemeste water 'n relatief laer produksie gelewer en is 1 ton/hektaar minder beet geproduseer as waar varswater gebruik is.

TABEL 2

Produksies van vyf verskillende groentesoorte wat met eendemis- en varswater besproei is.

Resultate word uitgedruk in produksie per hektaar

\begin{tabular}{|c|c|c|c|c|c|}
\hline \multirow[t]{2}{*}{ Groente } & \multirow{2}{*}{$\begin{array}{c}\text { Relatiewe } \\
\text { grootte van } \\
\text { persele }\left(\mathrm{m}^{2}\right)\end{array}$} & \multicolumn{2}{|c|}{ Eendemiswater } & \multicolumn{2}{|c|}{ Varswater } \\
\hline & & $\begin{array}{l}\text { Produksie } \\
\text { in } \\
\mathrm{kg} / \text { perseel }\end{array}$ & $\begin{array}{l}\text { Produksie } \\
\text { in } \\
\text { ton/hektaar }\end{array}$ & $\begin{array}{l}\text { Produksie } \\
\text { in } \\
\mathrm{kg} / \text { perseel }\end{array}$ & $\begin{array}{c}\text { Produksie } \\
\text { in } \\
\text { ton/hektaar }\end{array}$ \\
\hline Beet & 2220 & 7105.2 & 32.0 & 7281.6 & 32.8 \\
\hline Slaai & 1110 & 6338.1 & 57.1 & 5860.8 & 52.8 \\
\hline Aartappels & 2780 & 10591.8 & 38.1 & 11648.2 & 41.9 \\
\hline Spinasie & 1670 & 9301.9 & 55.7 & 6880.4 & 41.2 \\
\hline Tamaties & 2220 & 21267.6 & 95.8 & 14319.0 & 64.5 \\
\hline Totaal & 10000 & 54604.6 & & 45990.0 & \\
\hline
\end{tabular}

\section{Visproduksie in behandelde rioolwater met byvoeding}

\section{Monokultuurproduksie met karp en baber}

Volgens figuur 4 was dit moontlik om $3263 \mathrm{~kg}$ karp per hektaar te produseer teen 'n digtheid van 10000 vis per hektaar oor 'n periode van 126 dae. Die gemiddelde watertemperatuur was slegs vir 83 dae hoër as $20^{\circ} \mathrm{C}$. 'n Gemiddelde voeromset van $2,5: 1$ is vir $C$. carpio oor die 126 dae produksieperiode behaal. Met 'n daling in die gemiddelde watertemperatuur onder $20^{\circ} \mathrm{C}$, is 'n merkbare verswakking in die voeromset waargeneem. Produksie van C. gariepinus onder parallelle toestande (figuur 4), was ietwat swakker met 'n totale produksie van $2824 \mathrm{~kg}$ vis per hektaar. Die gemiddelde voeromset $(x=8,2: 1)$ was ook heelwat swakker en dit is duidelik dat 'n watertemperatuur van laer as $20^{\circ} \mathrm{C}$ 'n ernstige nadelige invloed op voeromset tot gevolg gehad het.

\section{Polikultuurproduksie met karp en baber}

Deur gebruik te maak van oorwinterde en groter vis en deur die produksieproewe uit te voer onder gemiddelde watertemperature hoër as $20^{\circ} \mathrm{C}$, kon die totale produksie 
van karp en baber in polikultuur oor 'n produksieperiode van 100 dae, verhoog word na 6152 ton per hektaar. Betekenisvol is die relatief lae gemiddelde voeromset van slegs 1,65:1 wat oor hierdie periode verkry is. Hierdie benadering om van oorwinterde kleinvis gebruik te maak, bied waarskynlik die oplossing om die beperkende invloed van lae watertemperature op volgehoue produksie van vis te oorkom.

Die resultate van hierdie eksperiment word in figuur 5 saamgevat.

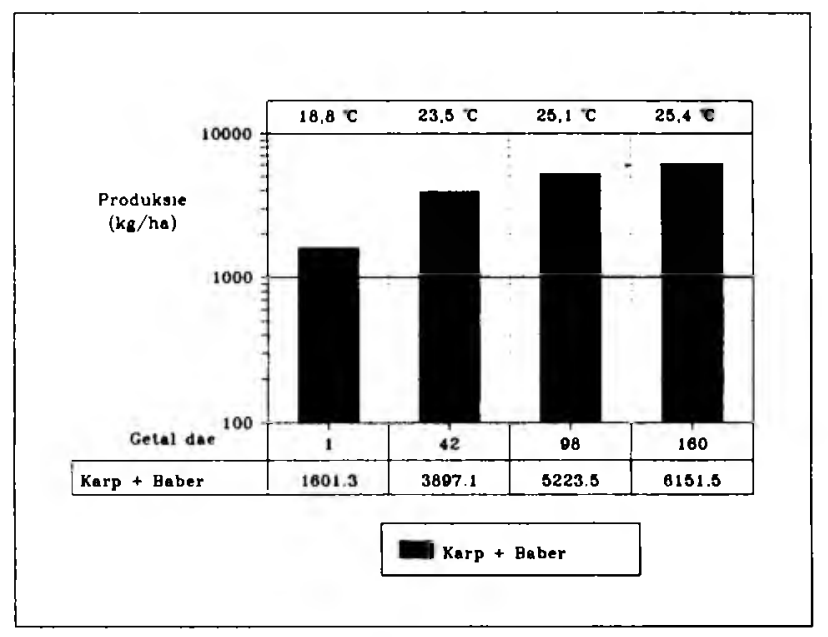

FIGUUR 5: Aanwending van behandelde rioolwater in die polikultuurproduksie van die karp $\mathrm{C}$. carpio en die baber $\mathrm{C}$. gariepinus oor 'n tydperk van 100 dae. 'n 18\%-proteienviskos is as byvoeding gebruik. Gemiddelde watertemperature vir elke tydperk in ${ }^{\circ} \mathrm{C}$.

\section{BESPREKING}

Die aanvaarbaarheid van varswatervis deur die landelike bevolking in ontwikkelende gebiede is reeds deur 'n aantal marknavorsingsondersoeke bewys. ${ }^{56,57,58}$ Grootskaalse benutting van varswatervis deur swart gemeenskappe word tot 'n groot mate deur produksiekostes bepaal. Die belangrikste faktor wat die prys van akwakultuurgeproduseerde varswatervis beïnvloed, is die kostes van gebalanseerde kunsmatige diëte. Die toevoeging van landbouafvalstowwe en die benutting van behandelde rioolafloopwater as 'n vorm van nutriënte in 'n visdam-ekosisteem, is 'n daadwerklike poging om op hierdie wyse te kompenseer vir die hoë produksiekostes van varswatervis. Die bykomstige voordele van die gebruik van bemeste water vir die besproeiing van groente en ander gewasse, is duidelik deur die huidige reeks ondersoeke bevestig. Dit bied die verdere voordeel dat visproduksie deur middel van akwakultuur (die onbekende) meer aanvaarbaar gemaak word vir die swart man deur dit te kombineer met groenteproduksie (die bekende).

Die huidige ondersoeke dui ook op die belangrikheid daarvan om gebruik te maak van oorwinterde jong vis.
Op hierdie wyse word die totale produksieperiode om vis markklaar te kry, aansienlik verkort en kon die visproduksieperiode saamval met daardie maande waar visdamwatertemperature gemiddeld hoër as $20^{\circ} \mathrm{C}$ was.

Die beste voedselproduksieresultate is verkry met 'n geïntegreerde sisteem waar vis-, eend- en groenteproduksie gekombineer is. Markondersoeke het duidelik aangetoon dat hierdie tipe van geïntegreerde vis-, eend- en groenteproduksiesisteme die mees aanvaarbare inslag sal vind onder plattelandse swart gemeenskappe, veral waar daar ' $n$ ernstige behoefte aan proteïene bestaan. Daarby hou 'n geïntegreerde voedselproduksiesisteem sonder twyfel die ekonomiesste voordeel in terme van totale produksiekostes en optimale waterbenutting in. Hierdie tipe sisteem het ook die verdere belangrike voordeel, $\mathrm{nl}$. dat al die vrygestelde mis direk in die water opgelos word en dus geen higiëniese probleem as afvalproduk, wat andersins die geval sou wees, veroorsaak nie.

Indien daar gekyk word na die keuse van visspesies vir produksiedoeleindes, is dit belangrik om in vispolikultuurproduksiesisteme, nie alleenlik van inheemse visse nie, maar ook van eksotiese vissoorte soos o.a. die Europese en Sjinese karpspesies gebruik te maak, wat elkeen 'n baie spesifieke voedingspatroon het en as sodanig die verskillende komponente van 'n visdam-ekosisteem optimaal benut.

In die voorafgaande is dit duidelik dat akwakultuur as sulks goed sal kan inskakel by bestaande en nuwe besproeiingskemas in plattelandse swart gebiede. Visproduksie deur akwakultuur is egter nog tot 'n groot mate 'n vreemde begrip vir die swart man en sal volgehoue kundige leiding steeds verskaf moet word om hierdie vorm van voedselproduksie suksesvol te bemeester.

Die suksesse al dan nie vir die vestiging van 'n ekonomies lewensvatbare akwakultuurindustrie in ontwikkelende landelike gebiede van Suid-Afrika sal verder bepaal word deur die invloed van tradisionele beskouinge van die swart man op dié tipe van ontwikkelingsprojekte. $^{59}$

\section{BEDANKINGS}

Die Universiteit van Transkei, die Randse Afrikaanse Universiteit en die Universiteit van die Noorde, asook die Departemente van Landbou van Transkei en Lebowa, word bedank vir apparaat, laboratoriumfasiliteite en damgeriewe wat hierdie ondersoeke moontlik gemaak het.

\section{LITERATUURVERWYSINGS}

1. Schoeman, J.H., Cloete, M. \& Nicholson, C. (1985). The population development programme : A challenge for the future, RSA 2000 . $7(2), 1-7$.

2. Department of Water Affairs. (1986). Management of water resources of the Republic of South Africa (CTP Bookprints, Cape Town).

3. Steyn, N.P., Badenhorst, C.J., Nel, J.H. \& Jooste, P.L. (1992). The nutritional status of Pedi preschool children in two rural areas of Lebowa, S.A. J. Fl. Sci. \& Nutr. 4(2), 24-28.

4. Dickson, I.F. (1981). Animal waste: A review of the extent and nature of the problem in South Africa, UOFS Publ. Series 3, 204-211. 
5. Barash. H. \& Schroeder, G.L. (1984), Use of fermented cow manure as a feed substrate for fish polyculture in stagnane water ponds, Aquaculture, 36, 127-140.

6. Woynarovich, E. (1956). Die Organische Düngung von Fischteichen in Produktions Biologischer Beleuchtung, Acta Agronom. Acad. Sci. Hung., 6(3-4), 443-474.

7. Woynarovich, E. (1957). Bedeutung der Carbodüngung von Fischteichen, Dtsch. Fisch. Zing., 4(1), 15-16.

8. Schroeder, G.L. (1978). Autotrophic and heterotrophic production of micro-organisms in intensely manured fishponds and related fish yield, Aquaculture, 14, 303-325.

9. Schroeder, G.L. \& Hepher, B. (1976). Use of agriculture and urban wastes in fish culture. FAO Tech. Pap., 76/e9, 1-3.

10. Moav, R., Wohlfarth, G., Schroeder, G.L., Hultata, G. \& Barash, H. (1977). Intensive polyculture of fish in freshwater ponds. 1. Substitution of expensive feeds by liquid cow manure, Aquaculture, 10, 25-43.

11. Steyn, D.J., Scott, W.E., Toerien, D.F. \& Visser, J.H. (1975) Eutrophication levels of some South African impoundments. I. Rietvlei Dam, Water $S A, 1(2), 45-52$.

12. Steyn, D.J., Toerien, D.F. \& Visser, J.H. (1975). Eutrophication levels of some South African impoundments. II. Hartbeespoort Dam. Water SA, 1(3), 93-101.

13. Steyn, D.J., Toerien, D.F. \& Visser, J.H. (1976). Eutrophication levels of some South African impoundments. IIl. Roodeplaat Dam. Water $S A, 2(1), 1-5$.

14. Steyn, D.J., Toerien, D.F. \& Visser, J.H. (1976). Eutrophication levels of some South African impoundments. IV.Vaal Dam, Water $S A, 2(2), 53-57$

15. Chimits, P. (1955). Tilapia and its culture: A preliminary bibliography, FAO Fish, Bull., 9(1), 1-33.

16. Jubb. R.A. (1967). Freshwater fishes of Southern Africa (Balkema, Cape Town), $248 \mathrm{pp}$

17. Bruton, M.N \& Boltt, R.E. (1975). Aspects of the biology of Tilapia mossambica Peters (Pisces: Chichlidae) in a natural freshwater lake (Lake Sibaya, South Africa), J. Fish. Biol., 7, 423-445

18. Bowen, S.H. (1981). Digestion and assimilation of perophytic detrital aggregate by Tilapia mossambica, Trans. Amer. Fish. Soc., $110,239-245$.

19. Du Plessis, S.S. \& Groenewald, A.A. (1953). The kurper of Transvaal, Fauna and Flora, 4(3), 35-43.

20. Chen. T.P. (1976). Aquaculture practices in Taiwan (Page Bros. (Norwich) Ltd).

21. Spataru, P. (1977). Gut contents of silver carp Hypophthalmichthy's molitrix and some trophic relations to other fish species in a polyculture system, Aquaculture, 11, 137-146.

22. Stott. B. \& Buckley, B.R. (1978). A note on the growth of two exotics in England; the silver carp (Hypophthalmichthys molitrix Val.) and the bighead carp (Aristichthys nobilis Rich.), J. Fish. Biol., 12, 89-91.

23. Moskul, G.A. (1979). Feeding of two-year old silver carp and bighead carp in foraging lagoons of the Krasnodar area. Translated from Russian. Krasnodar, 37-41.

24. Leventer, H.(1979). Biological control of reservoirs by fish (Mikoroth water Co., Nazareth Elit. Israel), 71 pp.

25. Leventer, H.(1981). Biological control of reservoirs by fish, Bamidgeh, 33(1), 3-23.

26. Hepher, B. \& Pruginin,Y. (1981). Commercial fish farming with special reference to fish culture in Israel (John Wiley \& Sons.N.Y.) p. 261.

27. Cremer, M.C. \& Smitherman, R.O. (1980). Food habits and growth of silver and bighead carp in cages and ponds, Aquaculture, 20, 51-64.

28. Cross, D.G. (1969). Aquatic weed control using grass carp, J. Fish. Biol., 599-605.

29. Stott, B. (1979). Turning weeds into cheap fish flesh, Fish Farmer. 2(2), 40-41.

30. Kilambi, R.V. (1980). Food consumption, growth and survial of grass carp Ctenopharyngodon idella Val. at four salinities. J. Fish. Biol., 17, 613-618.

31. Mitchell, C.P. (1980). Control of water by grass carp in two small lakes, New Zealand J. Mar. \& Freshwater Res., 14(4), 381-390.
32. Shelton, W.L., Smitherman, R. O. \& Jensen, G. L. (1981). Density related growth of grass carp Ctenopharyngodon idella (Val.) in managed small impoundments in Alabama, J. Fish. Biol., 18, 45-51

33. Schoonbee, H.J., Vermaak, J. \& Swanepoel, J.H. (1985). Use of Chinese grass carp Ctenopharingodon idella, in the control of the submerged weed Potamogeton pectinatus in an inland lake in the Transvaal, South Africa. Proc. 4th Int. Symp. Biol. Contr. Weeds, 19-25. August 1984, Vancouver, Canada. Delfosse, E.S. (ed.), Agric. Can., 557-565.

34. Venter, A. J. A. \& Schoonbee. H. J. (1991). The use of triploid grass carp, Ctenopharyngodon idella (Vai.) in the control of submerged aquatic weeds in the Florida Lake, Roodepoort, Transvaal, Water $S A, 17(4), 321-326$.

35. Liao, C. K. (1955). On the productivity of two experimental fish ponds managed with traditional methods of Chinese piscicultre, Acta Hydrobiologica Sinica. 1

36. Buys, J.C. (1985). 'n Ondersoek na biologiese en ander beheermaatreëls vir die bekamping van varswaterslakke in visdamme. M.Sc.-verhandeling, RAU.

37. Zur, O. (1980). The importance of chironomid larvae as natural feed and as a biological indicator of soil conditions in ponds containing common carp Cyprinus carpio) and Tilapia (Sarotherodon aureus), Bamidgeh, 32(3), 66-77.

38. Prinsloo, J.F., Schoonbee, H.J. \& Nxiweni, J.S. (1981). Some observations on biological and other control measures of the African clawed frog Xenopus laevis (Daudin) Pipidae, Amphibia) in Fish ponds in Transkei, Water $S A, 7(2), 88-96$

39. Prinsloo, J. F., Schoonbee, H. J., \& Theron, J. (1989). The use of the sharptooth catfish, Clarias gariepinus (Burchell) in the evaluation of cannibalism amongst juveniles of this species, Water SA, 15(3), 179-189.

40. Hey, D. (1945). Inland Fisheries Department Report 1944/1945. Prov. Admin. of the Cape of Good Hope, 31-32.

41. Schoonbee, H.J., Brandt, F. de W. \& Bekker, C.A.L. (1978). Induced spawning of the two phytophagous Chinese carp species Ctenopharyngodon idella (Val.) and Hypophthalmichthys molitrix (Val.) with reference to the possible use of the grass carp in the control of aquatic weeds, Water $S A, 4(2), 93-103$.

42. Brandt, F. de W. \& Schoonbee, H. J. (1980). Further observations on the induced spawning of the phytophagous Chinese carp species Ctenopharyngodon idella (Val.) and Hypophthalmichthys molitrix (Val.), Water $S A, 6(1), 27-30$.

43. Schoonbee, H.J., Hecht. Y., Polling, L. \& Saayman, J.E. (1982). Induced spawning of the sharptooth catfish Clarias gariepinus with notes on techniques employed in the removal of egg adhesiveness. In: Reproductive Physiology of fish, Richter, C. J. J. \& Goos, H. J. Th. eds. (Pudoc. Publ. Wageningen, Netherland).

44. Prinsloo, J. F. \& Schoonbee, H. J. (1983). Induced spawning of the Chinese bighead carp Aristichthys nobilis (Richardson) at the Umtata dam fish research station, S. Afr. J. Sci., 79(5), 229-231.

45. Schoonbee, H.J. \& Prinsloo, J.F. (1984). Techniques and hatchery procedures in induced spawning of the European common carp Cyprinus carpio and the Chinese carps Ctenopharyngodon idella, Hypophthalmichthys molitrix and Aristichthys nobilis in Transkei, Water $S A, 10(1), 36-39$.

46. Schoonbee, H.J. \& Prinsloo, J.F. (1986). Use of the pituitary glands of the sharptooth catfish Clarias gariepinus in the induced spawning of the European common carp, Cyprinus carpio and the Chinese grass carp, Ctenopharyngodon idella in Transkei, Water $S A, 12(4), 235-237$.

47. Prinsloo, J.F., Schoonbee, H.J., Polling, L. \& Viljoen, R. (1987). Notes on the use of hatching trays in the breeding of European common carp Cyprinus carpio L., Water SA, 13(3), 185-188.

48. Polling, L., Van der Waal, B.C.W. \& Schoonbee, H.J. (1987). Improvements in the large scale propagation of the sharptooth catfish Clarias gariepinus (Burchell) in South Africa, S. Afr. J. Anim. Sci., 17(4), 176-180.

49. Prinsloo, J. F., Hoffman, L. C. \& Theron, J. (1993). A comparison of the humidity chamber. Marisource hatching tray and "Zuger" glass funnel incubation systems for large scale breeding of Cyprinus carpio and Clarias gariepinus, Water SA, 19(2), 167-170.

50. Prinsloo, J.F. \& Schoonbee, H.J. (1986). Comparison of the early larval growth rates of the Chinese grass carp Ctenopharyngodon 
idella and the Chinese silver carp Hyphophthalmichthy's molitrix using live and artificial feed, Water SA, 12(4), 229-234.

51. Prinsloo, J.F. \& Schoonbee. H.J. (1984). Observations on fish growth in polyculture during the late summer and autumn in fish ponds at the Umtata Dam Fish Research Centre, Transkei. Part III: The use of chicken manure with and without pelleted fish feed, Water $S A, 10(1), 30-36$.

52. Prinsloo, J.F. \& Schoonbec, H.J. (1984). Observations on fish growth in polyculture during the late summer and autumn in fish ponds at the Umtata Dam Fish Research Centre, Transkei. Part II: The use of cattle manure with and without pelleted fish feed, Water $S A, 10(1), 24-29$.

53. Prinsloo. J.F. \& Schoonbce. H.J. (1987). Investigations into the feasibility of a duck-fish-vegetable integrated agriculture-aquaculture system for developing areas in South Africa, Water $S A, 13(2)$, 109-118.

54. Prinsloo, J.F. Schoonbee. H.J., Van der Walt, I. H. \& Pretorius, M. (1089). Production of the sharptooth catfish Clarias gariepinus
(Burchell) and the European common carp Cyprinus carpio L. with artificial feeding in polyculture in maturation ponds at Seshego, Lebowa, Water $S A, 15(1), 43-48$.

55. Prinsloo, J.F. \& Schoonbee, H.J. (1992). Evaluation of the polyand monoculture production of the common carp Cyprinus carpio L. and the sharptooth catfish Clarias gariepinus (Burchell) in final effluent oxidation pond water of a sewage purification system, Water SA, 18(1), 7-12.

56. Roode, M.C. Investigations of fish production in the Transkei. Fort Hare papers, 341-356

57. Nakani, V.S. (1983). A preliminary investigation into the freshwater fish market in Transkei. Unpubl. rep. $14 \mathrm{pp}$.

58. Rose, A.J., Tapson, D.R. \& Jordaan, B.C. (1987). Report on the potential for the development of freshwater aquaculture in the Republic of Ciskei. Agricultural and Rural Development Research Institute. Fort Hare. $108 \mathrm{pp}$

59. Malan, J.S. (1988). The cosmological factor in development programmes, S. Afr. J. Ethnol., I1(2), 61-66. 